\title{
Kinerja usahatani dan pemasaran terong ungu di Kabupaten Kupang, Nusa Tenggara Timur
}

\author{
Diah Aprilia Bau Bani ${ }^{1}$, Doppy Roy Nendissa ${ }^{1 *}$, I Wayan Nampa ${ }^{1}$ \\ ${ }^{1}$ Program Studi Agribisnis, Fakultas Pertanian, Universitas Nusa Cendana, Kupang, Indonesia \\ *E-mail: roynendissa@staf.undana.ac.id
}

\begin{abstract}
Purple eggplant is becoming a popular plant cultivated, especially by small farmers in Kupang, East Nusa Tenggara (NTT). The purpose of this study was to measure the farm performance and marketing of purple eggplant. The research method used a survey method, using 46 sample farmers obtained by simple random sampling - the standard of eggplant cultivation measures farming performance. Business feasibility uses R/C ratio and marketing performance using Margin and Farmer Share (FS) and the marketing function. The results showed that the farming performance, as seen from the cultivation of purple eggplant, showed that every cultivation activity carried out by the farmer had almost fulfilled the ideal growth requirements according to the farmer's expectations with a production yield of 7.476 ton / 0.3ha. The income of purple eggplant farming is Rp. $3,033,840 /$ the land area/planting season once. Purple eggplant farming is feasible, indicated by R/C $>1-$ marketing of purple eggplant through 4 marketing channels. The marketing system for eggplant is quite good, as indicated by the FS of $41.66 \%$. Not many marketing functions are carried out at each stage so that not muchadded value is generated. It is necessary to improve the purple eggplant cultivation system and increase the marketing function to increase the added value of purple eggplant.
\end{abstract}

Keywords: farming performance, R/C ratio, marketing margin, FS, marketing function

Abstrak. Terong ungu menjadi tanaman yang mulai populer diusahakan terutama oleh para petani kecil di Kupang, Nusa Tenggara Timur (NTT). Tujuan penelitian ini untuk mengukur kinerja usahatani dan pemasaran terong ungu. Metode penelitian menggunakan metode survey, menggunakan 46 petani sampel yang diperoleh secara simple random sampling. Kinerja usahatani diukur dengan standar budidaya tamanan terong. Kelayakan usaha menggunakan R/C rasio dan kinerja pemasaran menggunakan Margin dan Farmer share (fs) serta fungsi pemasaran. Hasil penelitian ditemukan bahwa bahwa kinerja usahatani yang dilihat dari budidaya terong ungu menunjukkan bahwa setiap kegiatan budidaya yang dilakukan oleh petani sudah hampir memenuhi syarat tumbuh ideal sesuai harapan petani dengan hasil produksi sebesar 7,476ton/0,3ha. Pendapatan usahatani terong ungu sebesar Rp.3.033.840/perluas lahan/satu kali musim tanam. Usahatani terong ungu layak diushakan, ditunjukan oleh R/C $>1$. Pemasaran terong ungu melalui 4 saluran pemasaran. Sistem pemasaran terong cukup baik, ditunjukkan oleh fs sebesar 41,66\%. Fungsi pemasaran tidak banyak yang dilakukan dalam setiap tahapan sehingga tidak banyak nilai tambah yang dihasilkan. Perlu ditingkatkan sistem budidaya terong ungu dan peningkatan fungsi pemasaran untuk menaikkan nilai tambah terong ungu.

Kata Kunci: kinerja usahatani, R/C ratio, marjin pemasaran, fs, fungsi pemasaran

\section{PENDAHULUAN}

Pertanian merupakan penggerak perekono-mian Nasional. Secara umum di Indonesia sektor pertanian berperan penting dalam peningkatan mutu hidup secara ekonomi dan juga mutu dari aspek sumber makanan (gizi) masyarakat. Oleh karenanya usaha peningkatan kesejahteraan dan kesehatan masyarakat difokuskan pada peningkatan kualitas dan kuantitas produksi pangan, salah satunya pada tanaman hortikultura, khususnya aneka sayuran yaitu sayur terong ungu. 
Usahatani menjadi matapencaharian bagi para petani. Di Kabupaten Kupang, produksi sayur mencapai 15.740 kuintal (1.574 ton). Sayur terong juga diproduksi oleh petani di Desa Pukdale Kecamatan Kupang Timur. Hasil produksinya mencapai 113,64 ton/7,4 ha (BPTP Penyuluhan Naibonat, 2018).

Petani sebagai pelaku usahatani, berperan dalam penyedia faktor produksi dan menjadi manajer. Usahatani tersebut guna memperoleh pendapatan untuk memenuhi kebutuhan hidup. Oleh karena itu, kinerja usahatani dan kinerja pemasaran menjadi peran penting.

Kinerja merupakan suatu hasil kerja yang telah dilakukan oleh seseorang atau individu dalam melakukan suatu pekerjaan, agar dapat tercapai tujuan dari suatu pekerjaan pekerjaan tersebut dan dapat meminimalisir biaya (Prastya, 2019). Kinerja usahatani dan kinerja pasar, menggambarkan bagaimana kerjasama antar faktor produksi, hasil produksi dan pemasaran hasil produksi, untuk petani memperoleh pendapatan optimal.

Penelitian tentang Pendapatan usahatani hortikultura terutama terong sudah banyak dilakukan di Indonesia baik terutama dalam skala usahatani sedang dan kecil. Penelitian pernah dilakukan oleh Cenik (2015) analisis usahatani dan faktor-faktor yang mempengaruhi penda-patan petani terong; Sulistiawan, et al (2016) tentang pengelolaan dan pendapatan usahatani terong ungu; Intisari (2017) menganalisis break even point usahatani terong; Marthalia, E. (2018), meneliti struktur biaya dan pendatan ussahatani terong; Thufeili, (2018) tentang pendapatan usahatani dan pemasaran terong ungu, melalui 4 rantai pemasan; Tanik, (2018) faktor-faktor yang mempengaruhi produksi usahatani terong ungu; dan Belta, et al (2018) menganalisis pendapatan usahatani sayur dan Situmorang, et al (2020), tentang kinerja usahatani dan kesejahteraan petani sayuran. Penelitian-penelitian tersebut umumnya mengukur pendapatan dan kelayakan usaha. Belum banyak yang mengaitkannya dengan aspek pemasaran. Penelitian ini mengukur kinerja usahatani (Budidaya terong ungu, pendapatan, R/C ratio (efisiensi) dan dikaitkan dengan kinerja pemasaran dan perilaku pasar.

\section{METODE}

Penelitian ini dilakukan di Kecamatan Kupang Timur, Kabupaten Kupang, dan pengambilan data dilaksanakan pada bulan Juli - Agustus 2019, menggunakan metode acak Multistage Sampling Techinique untuk medapat 46 responden. Kinerja usahatani diamati tahapan budidaya. Pendapatan dan kelayakan usaha terong menggunakan analisis R/C ratio. Pemasaran diukur melalui Farmer share $(F s)$, margin pemasaran dan mengamati fungsi-fungsi pemasaran. Kriteria jika $F s>40 \%$ dianggap baik efisien (Downey dan Erickson 1992).

\section{HASIL DAN PEMBAHASAN}

Kinerja Usahatani. Dalam kinerja usahatani, yang dibahas meliputi : (1) Budidaya terong ungu; (2) Biaya produksi, penerimaan dan pendapatan; (3) efisiensi ( $\mathrm{R} / \mathrm{C}$ ratio).

Budidaya Terong Ungu. Suatu keberhasilan usahatani terong di Desa Pukdale, dapat dilihat dari proses budidaya tanaman terong yang dibudidayakan. Tanaman terong ungu baik ditanam di pekarangan maupun di lahan produktif. Kebutuhan benih $40 \mathrm{gr}$ biji/0,3 ha. Sebelum benih ditanam, terlebih dahulu dilakukan persemaian bibit.

1) Pembuatan lahan tanam terong, yaitu dengan membuat larikan, dengan jarak antar larikan adalah 25-30 cm dengan kedalaman sekitar $30 \mathrm{~cm}$, lebar larikan $30 \mathrm{~cm}$ dan jarak antar larikan adalah 30 $\mathrm{cm}$. Tinggi larikan kurang lebih $30 \mathrm{~cm}$ dan jarak antar lubang tanam $50 \mathrm{~cm}$. Sehingga terdapat 210/0,3 ha dengan jumlah pohon 2.100/0,3ha.

2) Pupuk yang digunakan oleh petani di desa Pukdale adalah Urea dan Phonska setelah melakukan penanaman. Dua minggu sebelum tanam, lubang tanam diberi pupuk 0,5gr/lubang.

3) Terong ditanam pada larikan yang telah disediakan. Bibit tanaman siap dipindahkan ke lubang tanam setelah berumur 1,5 bulan sejak disemaikan atau kurang lebih berdaun 4 helai.

4) Pemeliharaan tanaman, kegiatan pemeliharaan tanaman meliputi:

a. Pengairan diberikan mulai dari pemindahan bibit, sampai pada lahan tanam. Pemberian air pada tanaman oleh petani yaitu pada pagi hari dan sore hari.

b. Tidak dilakukannya kegiatan penyulaman, karena semua bibit dan benih yang digunakan sudah terpakai semua. Sehingga pertumbuhan semua tanaman tidak merata.

c. Pembumbunan digunakan untuk menghindari adanya genangan air yang mungkin terjadi yang dapat merusak perakaran. Sedangkan penyiangan dilakukan untuk membersihkan 
gulma-gulma yang juga tumbuh bersama dengan tanaman, agar tidak saling merebut unsur hara.

d. Pemupukan selanjutnya untuk sekali musim tanam adalah 50kg/0,3 ha dan Phonska 50kg/0,3 ha. dengan perbandingan 1:1. Terjadi 2 kali pemupukan. Yang pertama setelah tanaman berumur 14-15 hari dan yang kedua setelah tanaman berumur 60 hari.

e. Pengendalian hama dan penyakit, menggunakan pestisida. Pestisida yang digunakan, disesuaikan dengan jenis hama yang muncul, seperti terjadi pembusukan buah atau berulat sebelum panen. Pestisida yang digunakan chix, trisula, pounce, curacro dan cypermax. Penggunaan pestisida, dilakukan dengan cara campurkan larutan pestisida dan air, dengan perbandingan 1:5.

f. Terong yang sudah bisa dipanen adalah kulit buahnya sudah berwarna dan mengkilat, dagingnya tidak terlalu keras, buahnya berukuran sedang, buah dapat dipanen dua kali dalam seminggu. Setiap pohon menghasilkan buah sekitar 7 buah per pohon.

Biaya Usahatani Terong. Biaya usahatani yang dibahas meliputi:

(1) Biaya tetap. Biaya tetap, meliputi : biaya pajak lahan, biaya sewa lahan, niaya sewa alat pertanian, dan penyusutan alat pertanian.

Tabel 1. Rata-rata Biaya Tetap Pada Usahatani Terong di Desa Pukdale

\begin{tabular}{cccc}
\hline No & Jenis Biaya & $\begin{array}{c}\text { Total Biaya } \\
(\mathbf{R p})\end{array}$ & $\begin{array}{c}\text { Rata-Rata Biaya } \\
(\mathbf{R p})\end{array}$ \\
\hline $\mathbf{1}$ & Pajak Lahan & 2.882 .500 & 62.663 \\
$\mathbf{2}$ & Sewa Lahan & 1.050 .000 & 22.826 \\
$\mathbf{3}$ & Sewa Alat Pertanian & 12.770 .000 & 277.609 \\
$\mathbf{4}$ & Penyusutan Alat Perta. & 38.007 .569 & 826.251 \\
& Jumlah & $\mathbf{5 4 . 7 1 0 . 0 6 9}$ & $\mathbf{1 . 1 8 9 . 3 4 9}$ \\
\hline
\end{tabular}

Sumber : Data Primer Diolah, 2019

Tabel 1 menyajikan rata-rata biaya tetap usahatani di Desa Pukdale adalah sebesar 1.189.349. Biaya pajak lahan yaitu biaya yang dikeluarkan petani untuk membayar lahan yang dimiliki petani reponden setiap tahunnya. Biaya sewa lahan, yaitu bagi petani responden yang tidak memiliki lahan sendiri, sehingga ia harus menyewa lahan milik orang lain. Biaya sewa alat pertanian yaitu biaya yang dikeluarkan selama proses produksi untuk mengelola usahataninya, seperti traktor, mesin pompa air, tangki penyemprot dan pacul. Serta biaya penyusutan alat pertanian, yaitu biaya yang bisa dibilang dihitung dari umur ekonomis alat pertanian yang digunakan oleh petani.

(2) Biaya variabel. Biaya variabel meliputi : biaya benih, biaya pupuk, biaya pestisida, biaya bensin, biaya solar, biaya tenaga kerja dan biaya transportasi

Tabel 2. Rata-rata biaya variabel usahatani terong di Desa Pukdale Kecamatan Kupang Timur Kabupaten

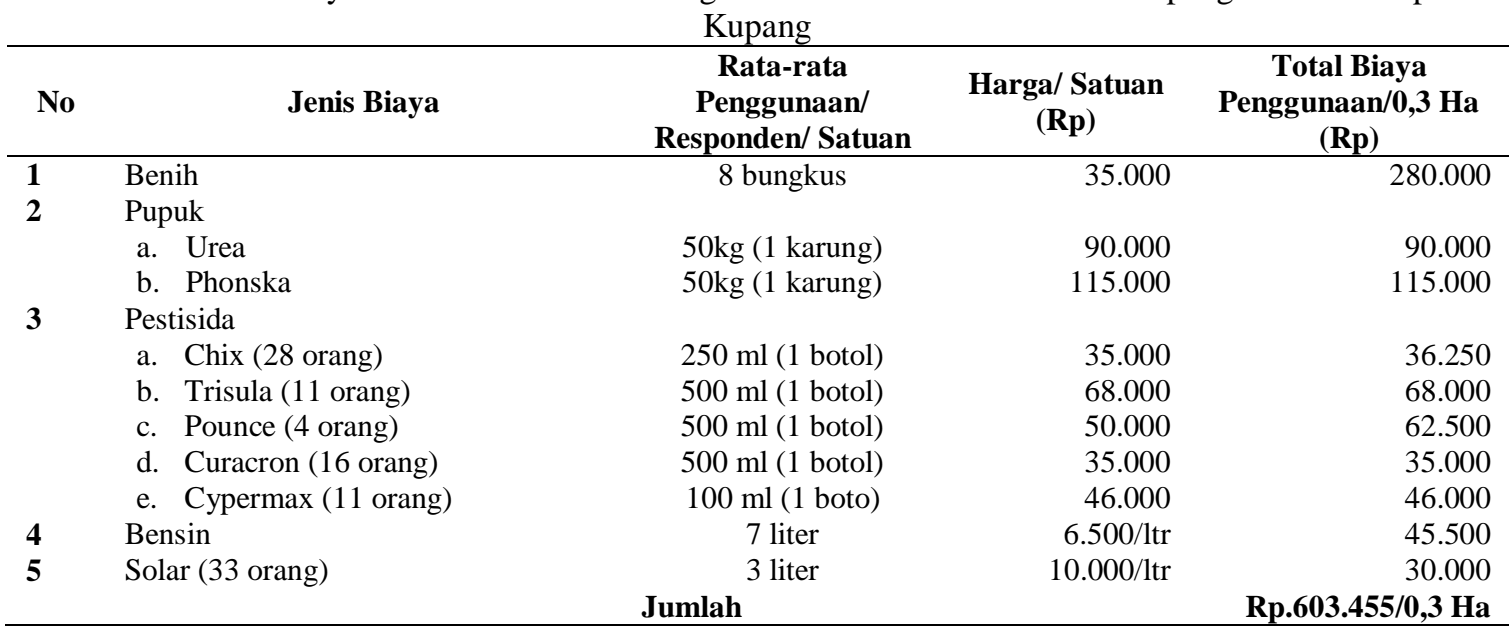

Sumber : Data Diolah, 2019 
Tabel 2 menunjukkan bahwa rata-rata biaya benih yang digunakan oleh petani responden adalah sebesar Rp. 280.000, dari rata-rata penggunaan benih adalah sebesar 8 bungkus, penggunaan pupuk masing-masing petani adalah 1 karung, dengan masing-masing harga 90.000/karung dan 115.000/karung. Rata-rata biaya penggunaan bensin sebesar Rp.45.500/0,3 ha dan solar sebesar Rp.30.000/0,3 ha. serta biaya tenaga kerja, yaitu: Biaya tenaga kerja yang dikeluarkan petani dihitung dengan menggunakan perhitungan HKO (Hari Kerja Orang) dikalikan dengan biaya per hari kerja, yaitu Rp. 10.000/hari. Sehingga rata-rata biaya tenaga kerja untuk membantu petani dalam menjalankan usahataninya. Biaya transportasi, yaitu biaya yang dikeluarkan saat menjual hasil produksi usahatani terong. Rata-rata biaya transportasi adalah sebesar Rp. 290.217. Biaya variabel yang digunakan oleh petani responden sebesar Rp. 2.287.486. Hal sebanding dnegan penelitian yang dilakukan oleh Dewi (2017), dimana biaya usahatani yaitu meliputi biaya tetap dan biaya variabel.

Pendapatan. Pendapatan petani diper-oleh dari selisih penerimaan usahatani dan biaya usahatani. Rata-rata penerimaan petani per responden adalah sebesar Rp. 5.802.966 dan rata-rata biaya produksi/biaya usahatani yang terdiri dari biaya tetap dan biaya variabel adalah sebesar Rp.2.769.126. Sehingga dapat diperoleh rata-rata pendapatan petani adalah sebesar Rp. 3.033.840. Hal ini sebanding dengan penelitian yang dilakukan oleh Sundari, M (2007), yaitu pendapatan yang diterima oleh petani Rp.7.456.350,45/Ha lebih besar dari biaya total produksi usahatani Rp. 4.760.703,81/Ha.

Efisiensi Usahatani terong ungu (R/C ratio). Hasil analisis data didapatkan $\mathrm{R} / \mathrm{C}$ ratio usahatani terong ungu sebesar 2,1. Artinya, setiap penambahan Rp. 1,- biaya yang dikeluarkan petani untuk usahatani terong ungu, maka menghasilkan keuntungan sebesar Rp. 2,1. Hal ini sejalan dengan penelitian yang dilakukan oleh Fadli (2014) yaitu usahatani tomat yang juga termasuk dalam tanaman hortikultura di Kelurahan Bayaoge layak untuk diusahakan, namun besar R/C rationya yaitu 1,76 < dibandingkan R/C ratio usahatani terong ungu di Kupang ini yang memiliki R/C rationya 2,1.

Kinerja Pemasaran. Kinerja pemasaran, meliputi, saluran pemasaran, marjin pema-saran, farmer's share, dan fungsi pemasaran. Saluran Pemasaran. Saluran pemasaran terong di Desa Pukdale, menghasilkan 3 saluran pemasaran. Hal ini sebanding dengan penelitian yang dilakukan oleh Utaminingsih, M yang juga memiliki 3 saluran pemasaran.

Saluran I : Petani - Konsumen

Saluran II : Petani - Pedagang -Pengecer - Konsumen

Saluran III : Petani - Pedagang Pengumpul - Pedagang Pengecer -Konsumen

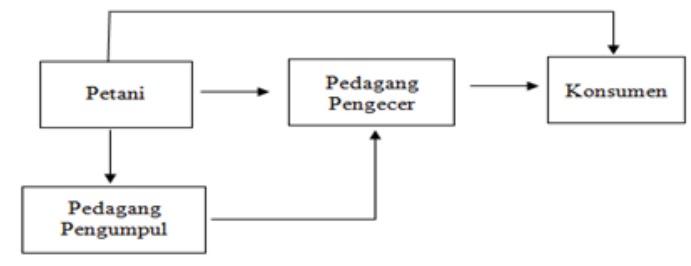

Gambar 1. Saluran Pemasaran Terong Kecamatan Kupang Timur Kabupaten Kupang.

Pada saluran pemasaran I, tidak ada lembaga pemasaran lain yang terkait dalam pemasaran produk pertanian sampai ke konsumen. Saluran pemasaran II, yang menjadi lembaga pemasaran pertama adalah pedagang pengecer. Pada saluran pemasaran III, yang menjadi lembaga pemasaran pertama adalah pedagang pengumpul. Dimana hasil produksi yang dijual petani ke pedagang pengumpul, kemudian dijual lagi dengan harga yang berbeda ke pedagang pengecer dan pedagang pengecer menjualnya ke konsumen.

Saluran pemasaran I adalah saluran pemasaran yang efisien, karena petani langsung menjual hasil produksi terong langsung ke konsumen akhir dengan harga jual Rp. 5.000/kg. Dari harga jual per kilogranm yang diberikan, sudah memberi keuntungan bagi petani maupun kepuasan bagi konsumen.

Marjin pemasaran. Margin pemasaran meru-pakan selisih harga ditingkat konsumen dengan harga yang diterima petani (Tomek dan Robinson, 1990). Dalam penelitian harga yang diberikan petani sebesar Rp.2.083/kg, sedangkan harga yang diterima konsumen adalah sebesar Rp.5.000/kg. 
Marjin pemasaran pada masing-masing lembaga adalah sebesar Rp.2.917 marjin antar petani dan konsumen, Rp.2.000 marjin antar pedagang pengumpul dan konsumen, serta Rp.1.000 marjin antar pedagang pengecer dan konsumen akhir.

Farmer's share. Merupakan bagian yang diterima petani. Pemasaran terong ungu di Dsea Pukdale petani, memiliki nilai share diatas $40 \%$, sebesar yaitu 41,66\%. Sehingga pemasaran tersebut sudah efisien, karena hasil analisis share-nya memiliki nilai diatas $40 \%$, yaitu lebih besar dari nilai kaidah efisiensi pemasaran menurut Downey dan Erickson (1992). Hal ini sebanding dengan penelitian yang dilakukan oleh Kusmawati (2016) yaitu pemasaran usahatani cabai merah yang merupakan tanaman hortikultura sayur sudah efisien, namun besar nilai sharenya $59,52 \%$.

Perilaku Pasar (Fungsi Pemasaran). Fungsi pemasaran, meliputi fungsi pertukaran, fungsi fisik, dan fungsi fasilitas. Hal ini sebanding dengan penelitian yang dilakukan oleh Dewi (2017), untuk melihat kinerja pemasaran dari perilaku pasar, yaitu:

(1) Fungsi pertukaran, sebagian besar hasil panen produk terong dijual ke pedagang pengumpul dengan harga yang sudah ditentukan oleh petani. Dalam fungsi pertukaran ini terjadi transaksi antara petani, pedagang pengumpul dan pedagang pengecer.

(2) Fungsi fisik, Hasil produk sayur terong akan dijual dan diangkut menggunakan pickup ke pasar dengan biaya pemasaran yang sudah ditentukan bersama, ataupun pedagang datang sendiri ke petani maupun konsumen yang langsung ke petani untuk membeli produk sayur terong. Fungsi fisik pemasaran dalam pemasaran terong di Desa Pukdale adalah perlakuan khusus yang diberikan sebelum produk terong dipasarkan, seperti pensortiran atau memilih dengan melihat kondisi fisik produk terong dan penyimpanan dan transportasi.

(3) Fungsi fasilitas, hasil Produksi terong oleh petani terlebih dahulu disortir. Disortir artinya bahwa sebelum menjualnya petani harus melihat apakah hasil produk terong layak atau tidaknya untuk dipasarkan. Lewat pensortiran tersebut, petani juga dapat menentukan harga jual produknya. Setelah disortir produk sayur terong disimpan paling lama satu atau dua hari. Biaya-biaya yang diperlukan adalah biaya pengepakan seperti karung untuk diangkut ke pasar, plastik untuk dikepak saat dijual/dipasarkan ke konsumen dengan rata-rata biayanya sebesar Rp.1.000/kg dan karet untuk mengikat produk terong bagi pedagang pengecer maupun pedagang pengumpul dan biaya retribusi pasar, dengan rata-rata biaya Rp. 300,-/kg terong ungu.

\section{KESIMPULAN}

Kinerja usahatani terong ungu belum maksimal. Petani umumnya melakukan tahapan aktifitas proses produksi usahatani namun belum maksimal sesuai standar budidaya, sehingga produski diperoleh belum maksimal. Rata-rata pendapatan diperoleh dari usahatani sebesar Rp.3.033.840 perluas lahan dan usahanya dianggap layak $(\mathrm{R} / \mathrm{C}>1)$. Kinerja pemasaran, relatif baik jika dilihat dari besarnya Fs $(>40 \%)$, namun rantai pemasaran relatif panjang (4 saluran pemasaran). Fungsi-fungsi pemasaran relatif belum dijalankan masimal sehingga nilai tambah masih rendah. Disarankan perlu perbaikan proses budidaya usatani, dan perlu perbaikan sistem pemasaran dengan memperpendek matarantai penyaluran. Fungsi pemasaran masih perlu ditingkatkan guna menambah nilai tambah.

\section{DAFTAR PUSTAKA}

Belta, S. S., Sriyoto, S., dan M. Mustopa, R. (2018). Analisis Pendapatan Usahatani Sayur di Desa Pekalongan Kecamatan Ujan Mas Kabupaten Kepahiang Provinsi Bengkulu (Doctoral dissertation, Universitas Bengkulu). Undergraduated thesis, Universitas Bengkulu.

Dewi, I Made Tamba, MP. Putu Fajar Kartika Lestari, SP., M.Agb (2017). Kinerja Usahatani Padi Sawah (Kasus Subak Mambal, Kecamatan Abian Semal). Fakultas Pertanian. Universitas Mahasaraswati Denpasar. AGRIMETA. Vol 7. No.13. April 2017. ISSN: 2088-2521

Dewi, N., Yusri J., dan Saputra A. (2017) Analisis Struktur Perilaku dan Kinerja Pasar (Structure, Conduct And Market Performance) Komoditi Padi di Desa Bunga Raya Dan Desa Kemuning Muda Kecamatan Bunga Raya Kabupaten Siak. 2017. Jurnal Agribisnis Vol 19 No. 1 Juni 2017 ISSN P: 1412 - 4807 ISSN O: 2503-4375

Downey, W.D. dan Erickson, S.P. 1992. Manajemen Agribisnis. Erlangga. Jakarta.

Cenik, N. (2015). Analisis Usahatani dan Faktor-faktor Yang Mempengaruhi Pendapatan Petani Terung di Kecamatan Bulango Utara Kabupaten Bone Bolango. Skripsi, 1(614410014). UNG. Universitas Negeri Gorontalo. 
Fadli, S. Analisis Pendapatan dan Kelayakan Usahatani Tomat di Kelurahan Boyaoge Kecamatan Tatanga Kota Palu. 2014. J. Agroland 21 (1) : 45 - 48, April 2014,

Intisari, I. (2017). Analisis Break Even Point Usahatani Terung di Desa Tulungsari Kecamatan Sukamaju Kabupaten Luwu Utara. Journal TABARO Agriculture Science, 1(1), 59-66.

Kusmawati, L. 2016. Analisis Saluran Pemasaran Cabai Merah Varietas Tanjung 2 (Suatu Kasus Di Kelurahan Tamanjaya Kecamatan Tamansari Kota Tasikmalaya). Jurnal Ilmiah Mahasiswa AGROINFO GALUH Volume 4 Nomor 1, September 2017 